Acta Crystallographica Section B

Structural

Science

ISSN 0108-7681

Editor: Carolyn P. Brock

\title{
The crystal and molecular structure of cholest-4-en-3-one
}

\author{
G. M. Sheldrick, E. Oeser, M. R. Caira, L. R. Nassimbeni and R. A. Pauptit
}

This electronic document was scanned from an archival copy of material deposited to accompany a paper published in an IUCr journal. In many cases the only accessible copy was a microfilm of a poor-quality original. 


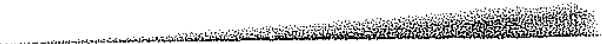

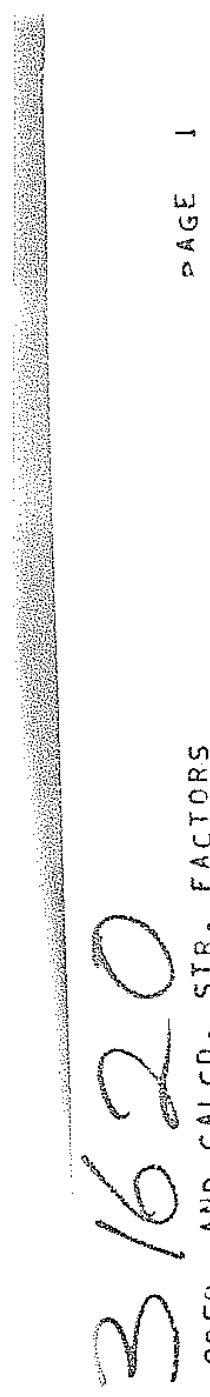

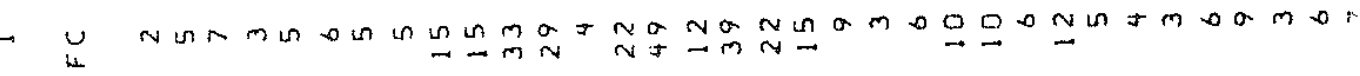

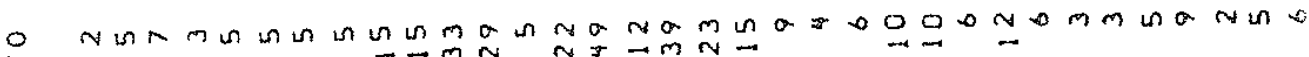

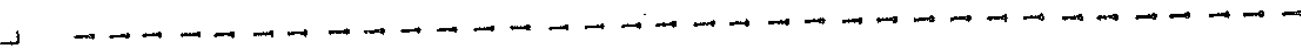

z.

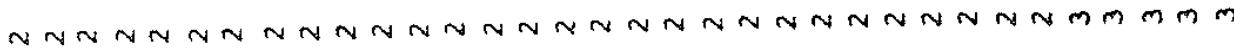

$x$

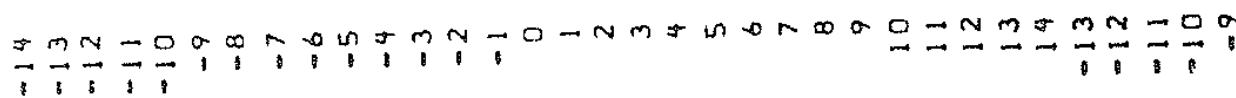

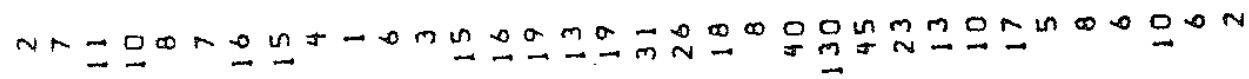

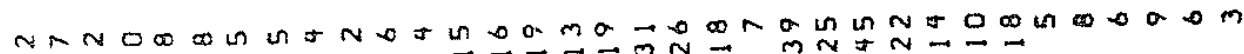

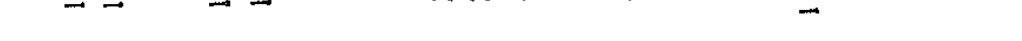

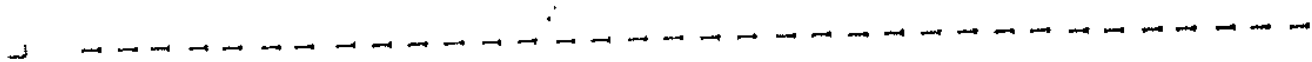

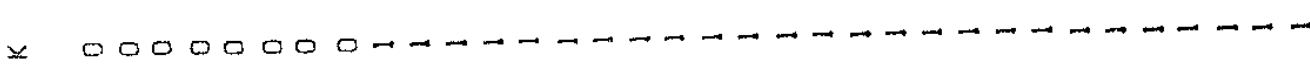

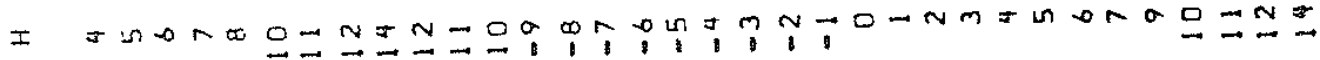

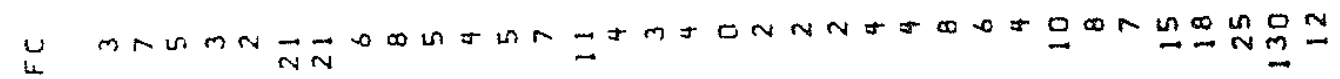

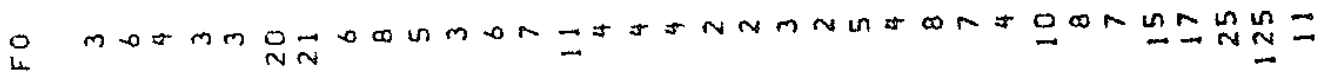

$\rightarrow 000000000000000000000000+\cdots-m-\cdots+\cdots$

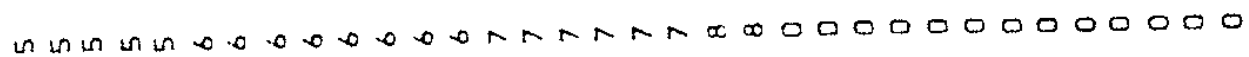

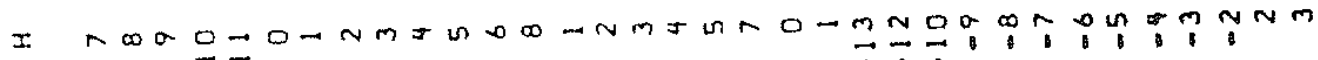

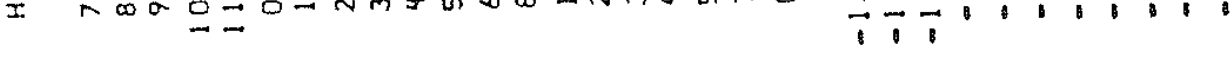

U m $m$ m

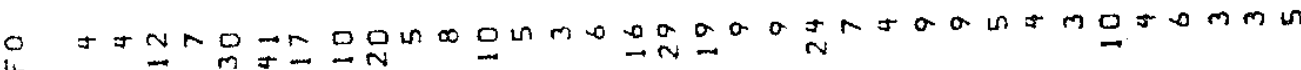
0000000000000000000000000000000000

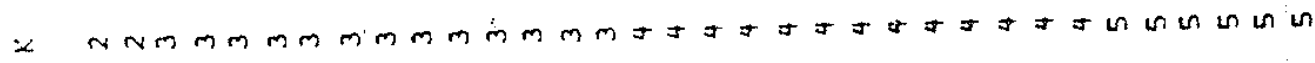

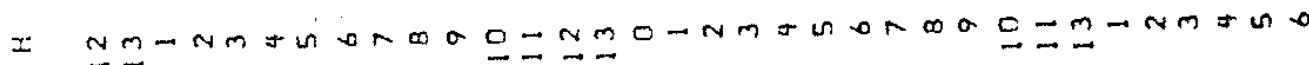

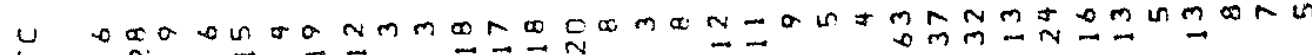

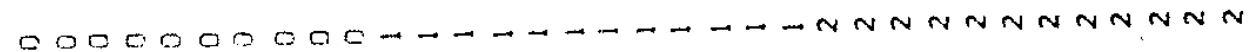

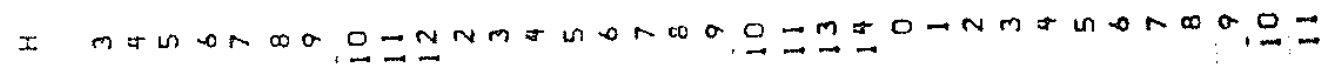




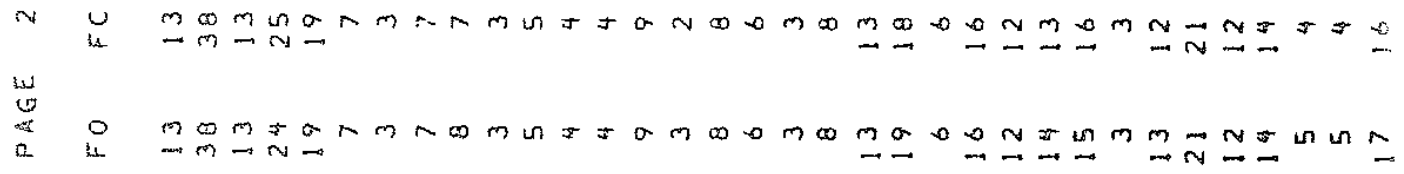

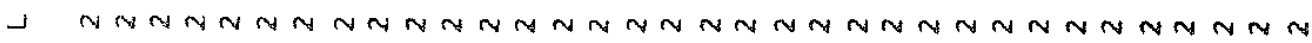

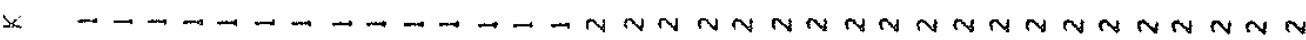

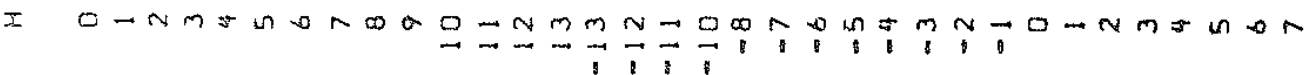

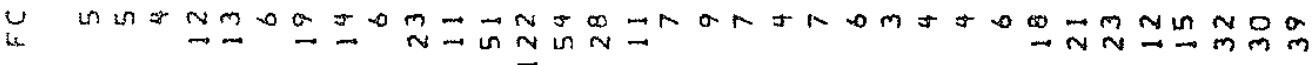

L $\quad$ in

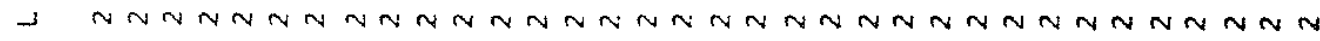

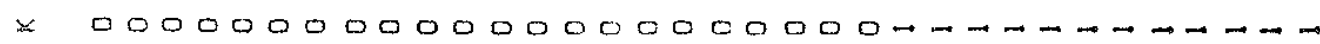

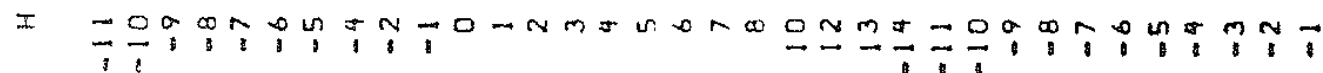

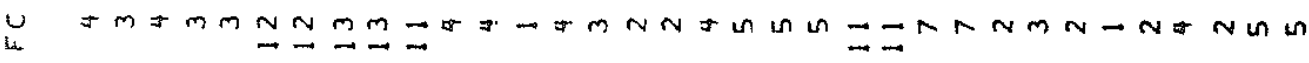

0 L

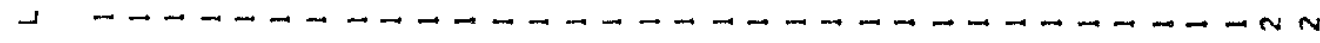

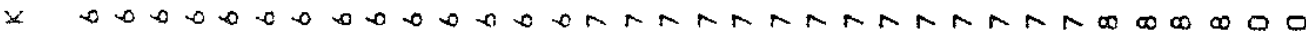

I

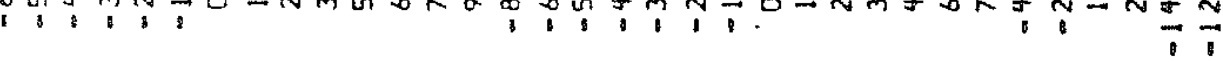

U $\quad$ I

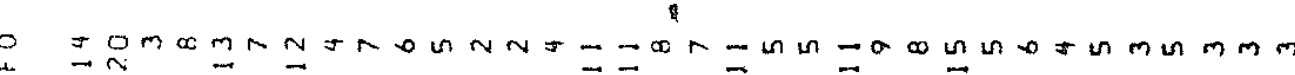

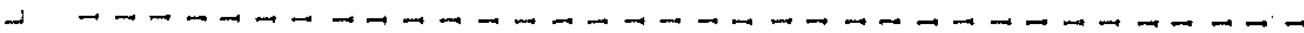

자

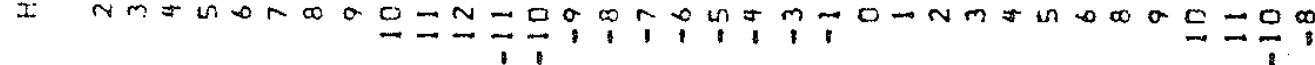

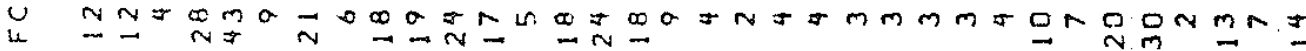

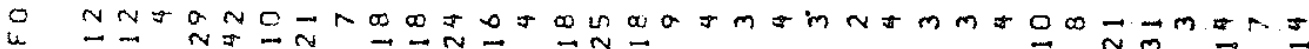

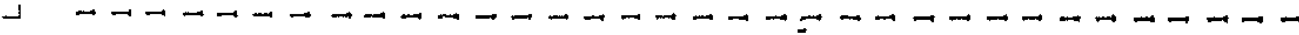

×

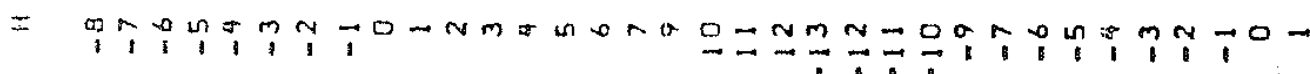




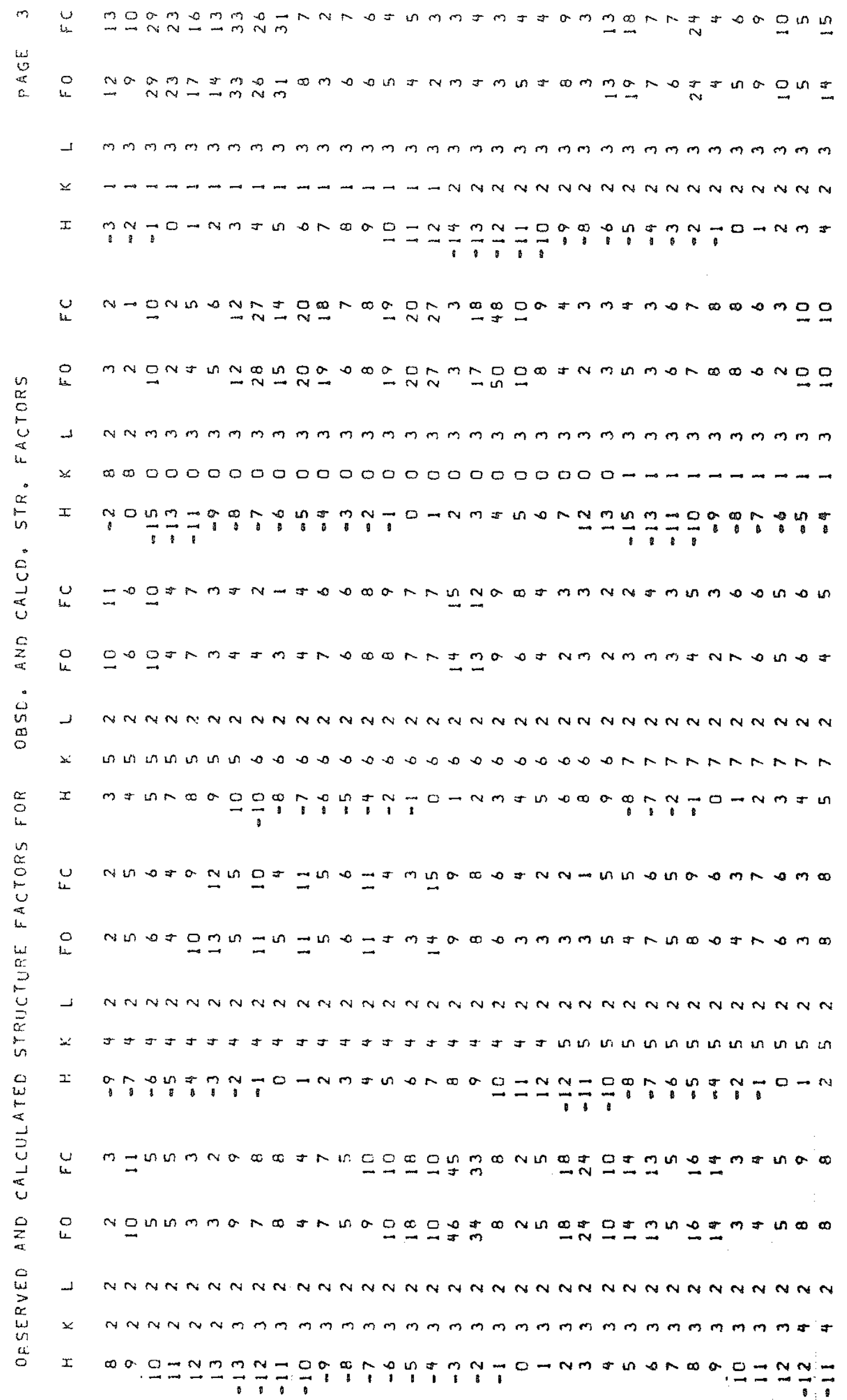




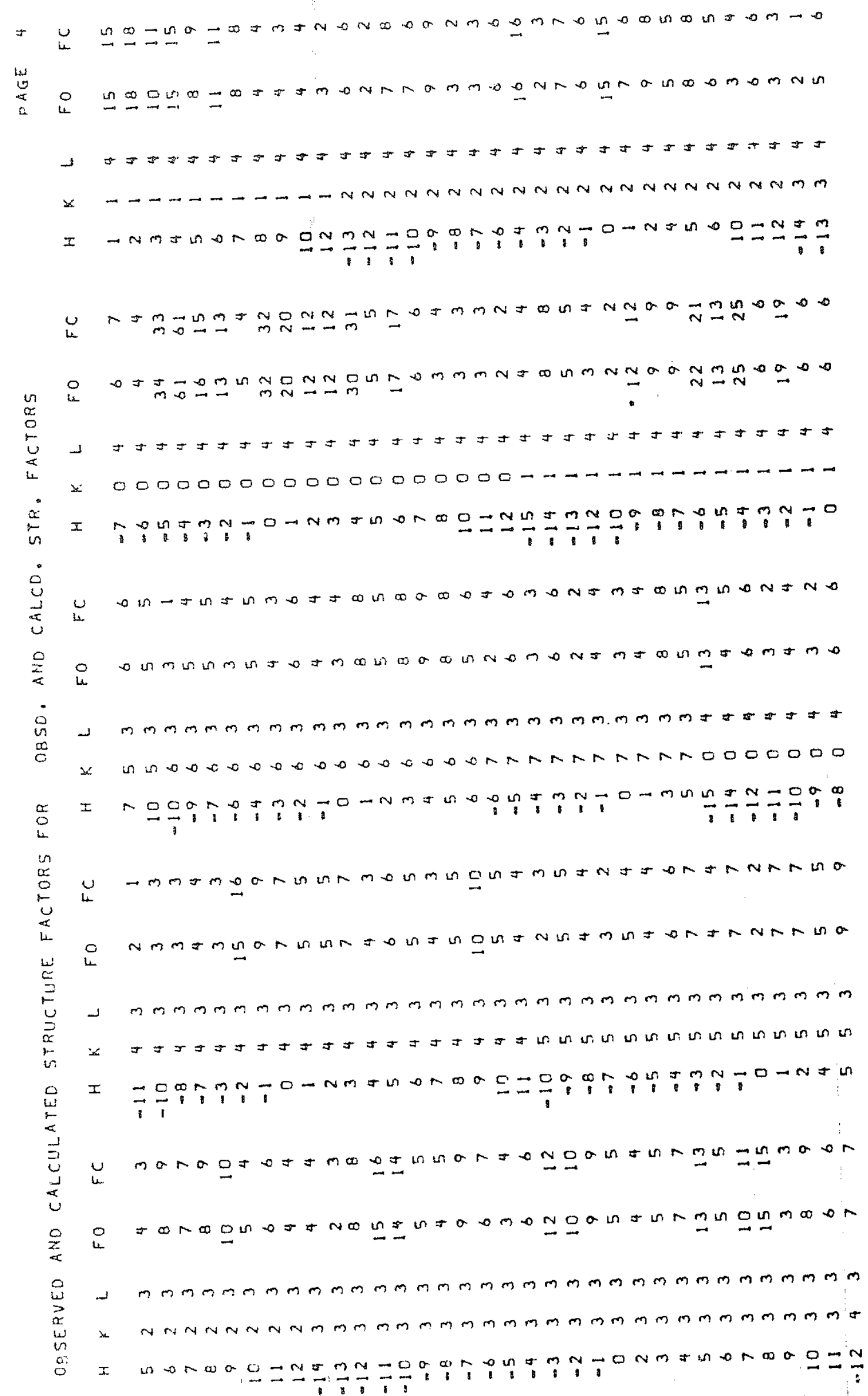




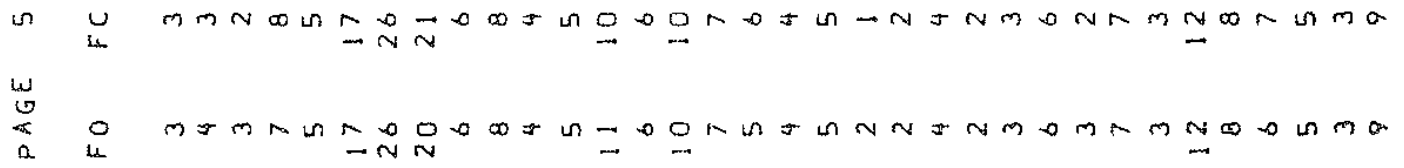

- in

x

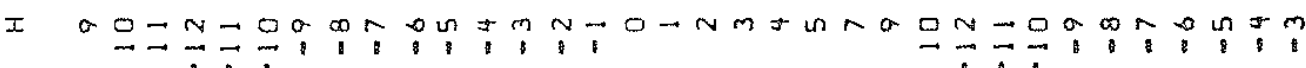

U.

1.

- แ

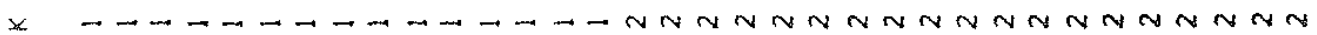
I $\quad 0$ J $m N-0 \rightarrow N m$ J

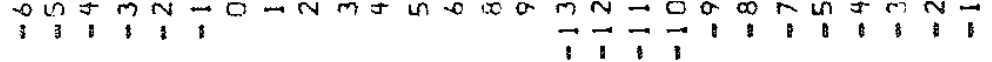

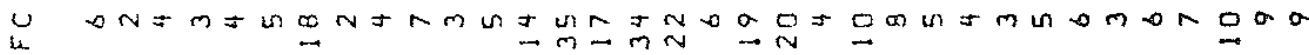

O

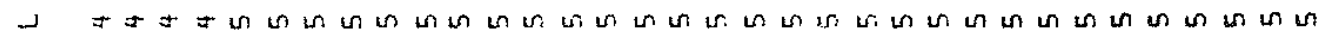

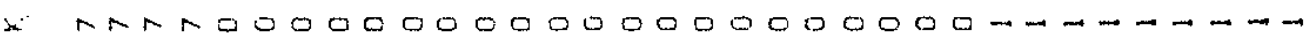
I

u $\quad 0$ แ

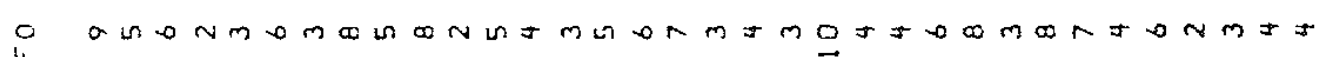

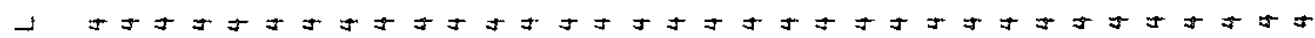

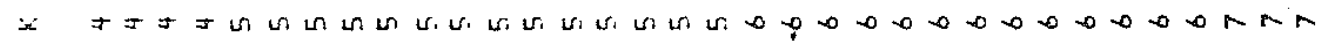

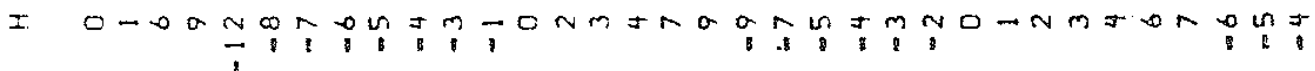

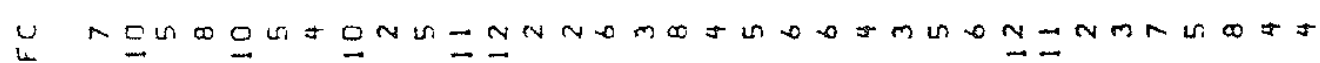

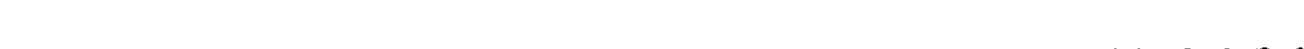

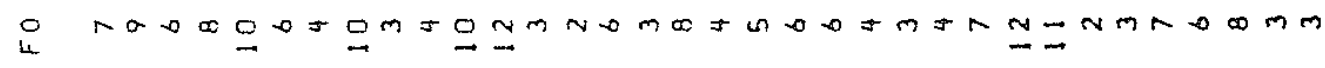

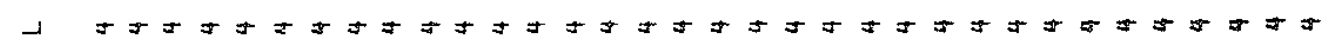

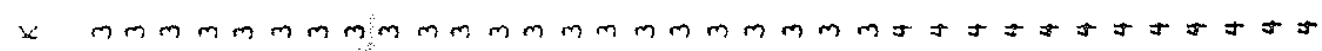

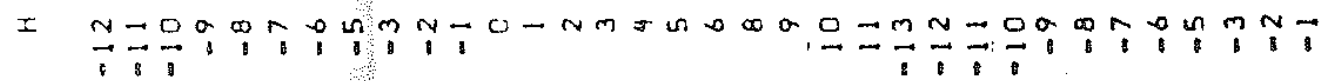




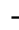

$$
I
$$

1.

○

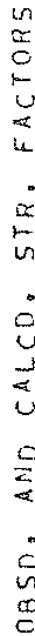

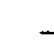




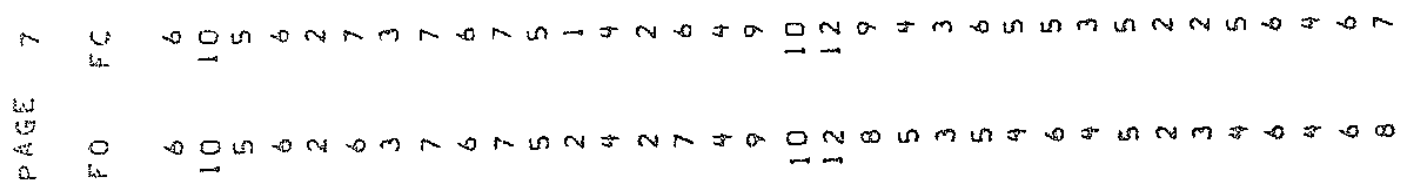

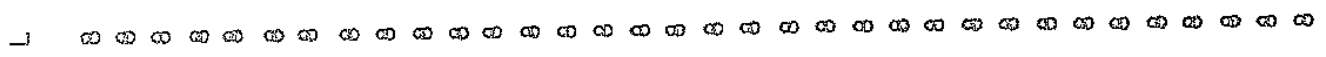

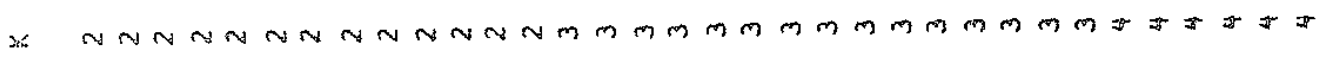

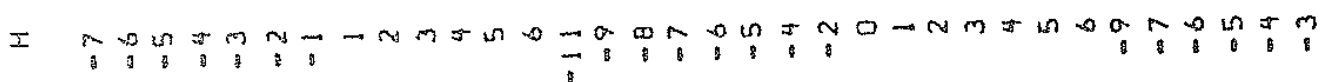

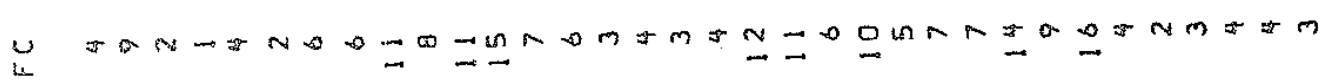

0 a

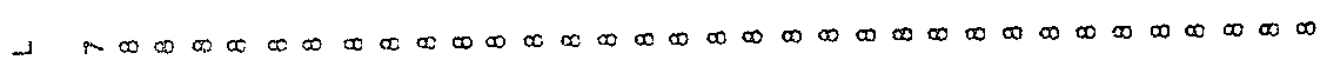

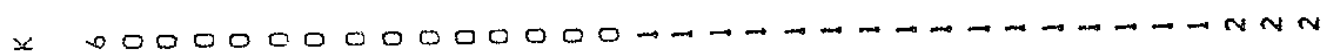

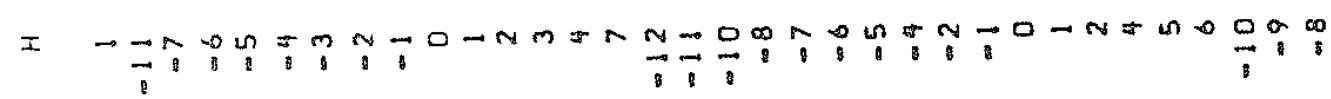

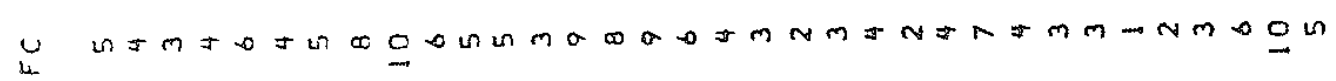

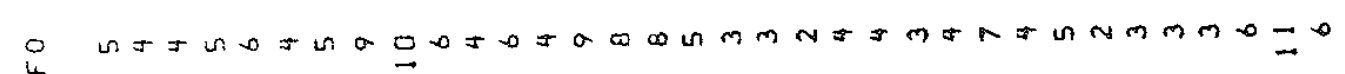

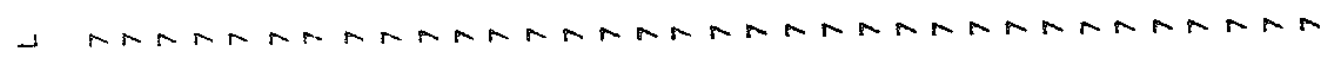

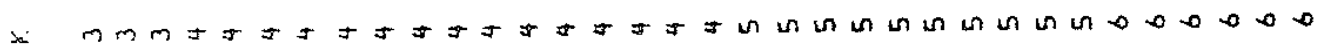

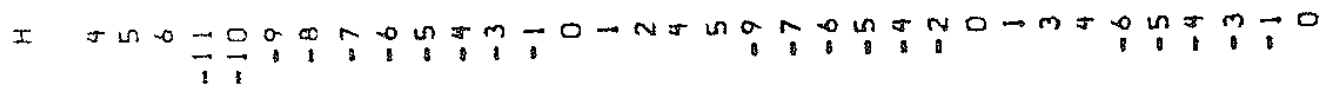
U. C $0 m m m$ L

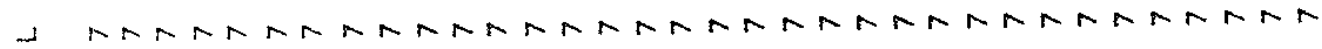

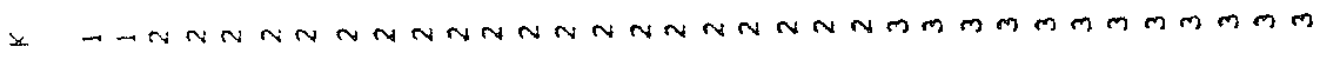

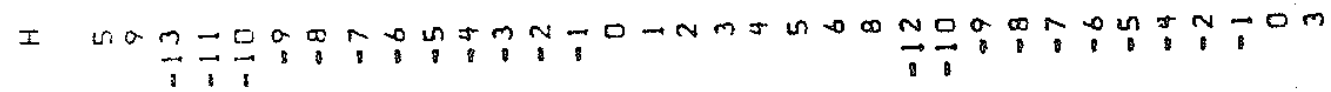
L ब o da

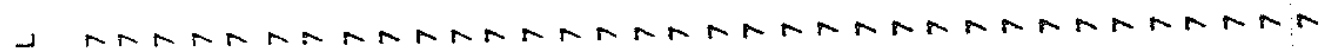

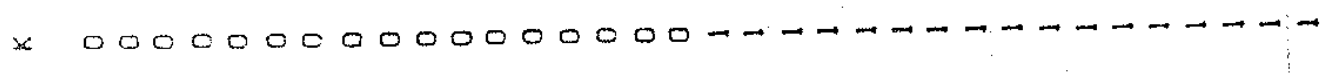

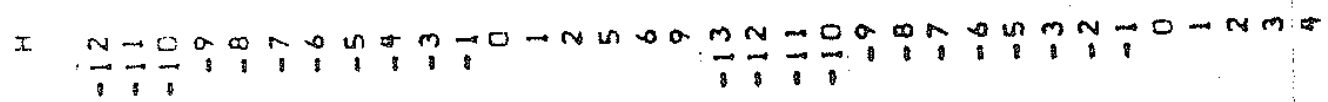

